\title{
A interferência das regras fonológicas e morfossintáticas do dialeto na aprendizagem do português padrão
} The interference of the phonological and morphosyntical rules of dialect in the learning of standard portuguese

\author{
La interferencia de las reglas fonológicas y \\ morfosintácticas del dialecto en el aprendizaje del \\ portugués estándar
}

\author{
Liliane Pereira \\ Universidade Estadual de Londrina (UEL), Londrina/PR - Brasil
}

\begin{abstract}
Resumo
Neste texto, pretendemos apresentar um mapeamento das capacidades de linguagem (DOLZ; SCHENEUWLY, 2004), especificamente a linguístico-discursiva nas produções iniciais, a partir de uma sequência didática do gênero carta do leitor. O objetivo é verificar os erros decorrentes da transposição dos hábitos da fala para a escrita (BORTONI-RICARDO, 2005). Como suporte teórico para análise dos dados, pautamo-nos no interacionismo sociodiscursivo (BRONCKART, 2003; 2006; 2008) e na sua proposta de engenharia didática (SCHNEUWLY; DOLZ, 2004). No que se refere à sociolinguística educacional, nos embasamos em Bortoni-Ricardo (2005); Coseriu (1980); Castilho (2010); Soares (2002); Cyranka (2014, 2015); Camacho (1988); e Faraco (2008).
\end{abstract}

Palavras-chave: Sociolinguística, Carta do leitor, Sequência didática.

\begin{abstract}
In this text, we intend to present a map of the language capacities (DOLZ; SCHENEUWLY, 2004), specially the linguistic-discursive one, in early productions from a didactical sequence of reader's letter genre. We aim to check the mistakes which result from the transposition of the speech habits to writing (BORTONIRICARDO, 2005). As a theoretical support for data analysis, we based the research on socio-discursive interactionism (BRONCKART, 2003; 2006; 2008) and in its didactic engineering proposal (SCHNEUWLY; DOLZ,2004). As far as educational sociolinguistics is concerned, the authors we have based on are Bortoni-Ricardo (2005); Coseriu (1980); Castilho (2010); Soares (2002); Cyranka (2014, 2015); Camacho (1988); Faraco (2008).
\end{abstract}

Keywords: Sociolinguistics, Reader's letter, Pedagogical sequence 


\section{Resumen}

En este texto, tenemos la intención de presentar un mapeo de las capacidades de lenguaje (DOLZ; SCHENEUWLY, 2004), específicamente la lingüístico-discursiva en las primeras producciones, a partir de una secuencia didáctica del género carta del lector. El objetivo es comprobar si hay errores derivados de la transposición de los hábitos del habla para la escritura (Bortoni-Ricardo, 2005). Como soporte teórico para el análisis de los datos, nos guiamos por el interaccionismo sociodiscursivo (BRONCKART, 2003; 2006; 2008) y por su propuesta de ingeniería didáctica (Schneuwly; DOLZ, 2004). Con respecto a la sociolingüística educativa, nos basamos en Bortoni-Ricardo (2005); Coseriu (1980); Castilho (2010); Soares (2002); Cyranka (2014, 2015); Camacho (1988); y Faraco (2008).

Palabras clave: Sociolingüística, Carta del lector, Secuencia didáctica

\section{Introdução}

Esta pesquisa nasceu de trabalhos com produção de texto, em uma escola pública de periferia, localizada na cidade de Londrina. Ao realizarmos o mapeamento inicial (DOLZ; GAGNON; DECANDIO, 2009), na produção escrita dos alunos, a fim de levá-los ao desenvolvimento de capacidades e, consequentemente, a melhorar a produção escrita, sempre observávamos muitas dificuldades quanto ao uso da norma padrão culta. Assim, na busca por uma explicação, constatamos que isso poderia estar ligado ao contexto no qual os alunos vivem. Boa parte desses alunos é bem carente, muitos vieram da zona rural ou têm pais que moraram no campo quando mais jovens.

As aulas de língua portuguesa, assim como das demais disciplinas, costumam ser dissociadas de suas determinações sociais e sociolinguísticas (SOARES, 2002), o que é preocupante, uma vez que a explicação e, até mesmo, uma possível superação do baixo rendimento da escola brasileira partem da aproximação com as camadas populares. As avaliações nacionais sempre trazem dados estatísticos apontando o fracasso escolar das escolas públicas, em especial as de periferia, mas poucos são aqueles que se interessam em saber o porquê de tal problemática. De maneira geral, o que vemos é que o conhecimento local, bem como as práticas letradas de determinados grupos são desvalorizadas pelos novos padrões que são introduzidos, como se as pessoas fossem "tábuas rasas", à espera da marca inaugural do letramento, como tanto dados oficiais parecem demonstrar (STREET, 2014). 
Dessa maneira, como aponta Geraldi (1984), é essencial que rompamos com o bloqueio de acesso ao poder, e, no que se refere a isso, a linguagem tem um papel de destaque. É o uso da língua na escola que traz à tona as diferenças entre os grupos sociais e que gera a discriminação e o fracasso, já que o uso de variantes estigmatizadas tem um valor negativo em relação às variantes sociais prestigiadas (SOARES, 2002). Assim, antes de tudo, é necessária uma organização curricular, culturalmente sensível, que procure levar em conta o contexto no qual o aluno está inserido, com o propósito de ampliar as competências de uso da língua materna da variante de prestígio, culta.

No que se refere à nossa pesquisa, pretendemos, tomando como base uma sequência didática ${ }^{1}$ do gênero carta do leitor, aplicada em uma turma do segundo ano do ensino médio de uma escola pública de periferia, apresentar o mapeamento das capacidades de linguagem (DOLZ;SCHENEUWLY, 2004). No caso desta pesquisa, trabalharemos com a capacidade linguístico-discursiva nas produções iniciais, com o objetivo de verificar os erros decorrentes da transposição dos hábitos da fala para a escrita (BORTONI-RICARDO, 2005). Em um segundo momento, pretende-se apresentar uma sugestão de trabalho, que leve em conta o desenvolvimento dessas (in)capacidades, pré-requisito essencial para a continuidade da sequência didática (DOLZ; GAGNON; DECANDIO, 2009).

Esta pesquisa é de caráter interpretativo, qualitativo e, como suporte teórico para análise dos dados, pautamo-nos nos fundamentos teórico-metodológicos do interacionismo sociodiscursivo (BRONCKART, 2003; 2006; 2008) e na sua proposta de engenharia didática (SCHNEUWLY; DOLZ, 2004). Quanto aos princípios da sociolinguística educacional, nos embasamos em Bortoni-Ricardo (2005); Coseriu (1980); Castilho (2010); Soares (2002); Cyranka (2014; 2015); Camacho (1988); Faraco $(2008 ; 2015)$.

\footnotetext{
${ }^{1}$ Conjunto de atividades pedagógicas, organizadas de maneira sistemática, cujo objetivo é oferecer ao aluno instrumentos importantes para melhorar sua capacidade de ler e escrever (DOLZ; NOVERRAZ; SCHNEUWLY, 2004).
}

Revista Educação Online Rio de Janeiro, n. 24, jan-abr 2017, p. 20-37 


\section{A sociolinguística no contexto escolar}

Como faremos uso dos pressupostos teóricos da sociolinguística em nossa pesquisa, faz-se importante esclarecer o que vem a ser a sociolinguística e a sua importância.

A sociolinguística, ramo pertencente à linguística, tem como principal foco a língua, a cultura e a sociedade e defende a ideia de que é no meio social que a interação acontece e, por consequência, as falas fluem.

Esse ramo de estudo pesquisa segmentos sociais que constroem e caracterizam a realidade e/ou o futuro linguístico de um povo. Nesse sentido, tem como propósito procurar compreender os fatores de variação e também a mudança linguística, analisando e divulgando as características da linguagem, da cultura e da sociedade pesquisada. Para Tarallo (2007), são considerados sociolinguistas todos aqueles que veem a língua como um veículo de comunicação, de informação e de expressão entre os indivíduos.

A sociolinguística compreende as pesquisas sobre: linguagem e língua; linguagem e preconceitos; linguagem e sociedade; linguagem e poder; linguagem e ensino; linguagem e qualidade de vida; linguagem e atitudes linguísticas; linguagem e percurso linguístico.

Ainda que o caráter da língua chamasse atenção, já no início do século $X X$, foi com William Labov que a sociolinguística passou a se destacar entre os estudiosos, uma vez que ele foi quem, segundo Tarallo (2007, p.7), "mais veemente, voltou a insistir na relação entre língua e sociedade e na possibilidade, virtual e real, de se sistematizar a variação existente e própria da língua falada".

O enfoque das pesquisas de Labov (1972) tem um caráter social e levam em conta a natureza heterogênea da língua. Nesse sentido, o autor defende a necessidade de se olhar para a natureza da linguagem em seu contexto sociocultural, para poder perceber as características sociais.

A concepção laboviana sustenta que a heterogeneidade é inerente ao sistema linguístico, compreendendo por sistema linguístico aquele manifestado no processo de comunicação, no uso real de falantes reais. O estudioso vê a língua como um sistema marcado por alterações, por variações ligadas à sociedade. Assim, sendo ela um fato social, considerá-la heterogênea é a melhor maneira de estudá-la e de conseguir mostrar as covariações das formas linguísticas. Labov também concebe a Revista Educação Online Rio de Janeiro, n. 24, jan-abr 2017, p. 20-37 
linguística como uma ciência social, o que implica em dizer, segundo Calvet (2002), que a "sociolinguística é a ciência" (p. 45).

O modelo laboviano trata a variação linguística como uma condição do sistema linguístico e afirma que as variantes da língua não são aleatórias, mas que há nelas certa regularidade e que estão sempre ligadas a fatores sociais. Tal modelo teórico-metodológico permite a compreensão das estruturas variantes existentes na língua e a observação dos mecanismos que regem as variações e as mudanças na língua, considerando-a em seu contexto social e cultural.

Partindo para o contexto escolar, a sociolinguística representa uma mudança nos conceitos tradicionais de transmissão da norma culta. O que quer dizer, em outras palavras, que a sociolinguística tem defendido um trabalho na escola que leve o aluno a conhecer a norma culta ${ }^{2}$, de forma a acrescentá-la ao português que já possuía. Nesse sentido, é preciso que os docentes instruam os falantes do português não padrão, habilitando-os ao uso da norma culta, sem preconceito linguístico. É preciso que o professor mostre ao aluno quando uma forma ou outra deve ser usada, fazendo, para isso, adaptação ao estilo, à circunstância etc.

$\mathrm{Na}$ sociedade como um todo, em especial na escola, em pleno século XXI, perpetua-se ainda a língua cultivada pela tradição gramatical. Segundo Dias (1996, p.19),

[...] a escola ainda opta somente pela veiculação da língua cultivada pela tradição gramatical, cristalizando a variedade padrão como única correta e excluindo as demais como "formas incorretas", "erros", "desvios". Em outras palavras, a escola considera a norma padrão-culta linguisticamente superior a todas as outras variedades.

Um dos caminhos para a melhora no ensino da língua materna é o desenvolvimento do caráter discursivo no educando. Baseado nesse pressuposto, os Parâmetros Curriculares Nacionais (PCN) sustentam que "o estudo da variação cumpre papel fundamental na formação da consciência linguística e no

\footnotetext{
${ }^{2}$ A expressão norma culta deve ser entendida à norma linguística praticada, em determinadas situações (aquelas que envolvem certo grau de formalidade), por aqueles grupos sociais mais diretamente relacionados com a cultura escrita. A norma padrão, apesar de muito próxima da norma culta, é um fenômeno relativamente abstrato, havendo um relativo apagamento de marcas dialetais muito salientes. O padrão tem sua importância e utilidade como força centrípeta no interior do vasto universo centrífugo de qualquer língua humana, principalmente, nas práticas de escrita (BAGNO, 2012).
}

Revista Educação Online Rio de Janeiro, n. 24, jan-abr 2017, p. 20-37 
desenvolvimento da competência discursiva do aluno, devendo estar sistematicamente presente nas atividades de língua portuguesa" (1997, p.81-82).

\section{Conversa com que entende: a heterogeneidade linguística}

Considerando que nosso instrumento de comunicação é a linguagem e que ela sempre está sujeita a mudanças por ser constitutiva do homem, a variação linguística é fundamental à linguagem (Labov, 1962). É por meio do contato entre os falantes que a língua se individualiza, modifica e varia. Entretanto, não é só pelo contato que a língua se modifica, mas também historicamente. De acordo com Camacho (1988, p. 29), "uma língua é um objeto histórico, enquanto saber transmitido, estando, portanto, sujeita, às eventualidades próprias de tal tipo de objeto." Isso quer dizer que se transforma no tempo e se diversifica no espaço.

Coseriu (1980) defende que a diversidade linguística pode ser resultante de diversos fatores e, assim, propõe as seguintes formas de variação: diacrônica, diatópica, diastrática e diafásica.

A variação diacrônica é aquela que se estabelece de acordo com o passar do tempo. Por exemplo, os jovens de hoje não usam muitos vocábulos e, até mesmo, gírias que seus pais e, muito menos, seus avós usavam.

Já a variação diatópica é uma diversidade linguística regional ou geográfica, apresentada por pessoas de diferentes regiões que falam a mesma língua. A variação diatópica está relacionada aos regionalismos ou falares locais. Esses falares indicam os costumes e a cultura de cada região. Para isso, podemos citar as diferenças do português falado no Brasil para o português falado em Portugal. De acordo com Castilho (2010, p.198), "de todas as variedades do português, a variedade geográfica é a mais perceptível". O autor menciona que a percepção da rica variedade geográfica brasileira levou vários estudiosos a se dedicarem aos estudos da dialetologia.

A variação diastrática se refere às diferenças entre os estratos socioculturais (nível culto, popular, língua padrão), ou seja, as variações que acontecem de um grupo social para outro. Para Castilho (2010, p.204),

analfabetos e cidadãos escolarizados não falam exatamente da mesma forma. Analfabetos usam o 'português popular', ou variedade não culta. Pessoas escolarizadas usam o 'português culto', ou variedade padrão, aprendida na escola ou no ambiente familiar.

Revista Educação Online Rio de Janeiro, n. 24, jan-abr 2017, p. 20-37 
Defende-se, nesse sentido, a importância de lutarmos contra o preconceito linguístico em relação a falantes do português popular, visto que se refere a uma norma tão completa e complexa como qualquer outra.

Quanto à variação diafásica, ela está ligada às distinções entre os diversos tipos de modalidade expressiva. Para Coseriu (1980, p.110-111), “as variedades linguísticas que caracterizam - no mesmo estrato social - os grupos 'biológicos' (homens, mulheres, crianças, jovens) e os grupos profissionais podem ser consideradas como 'diafásicas'”.

Entre os tipos de variação, Castilho (2010) faz menção ainda à variação de canal, que abarca as diferenças entre a escrita e a oralidade. Segundo ele, "a comunicação linguística pode ocorrer em presença do interlocutor, quando falamos, ou na sua ausência, quando escrevemos. Isso nos leva à variação de canal, a língua falada e a língua escrita" (p.212).

Assim, diante dessa diversidade linguística, nos bancos escolares, precisa-se romper com a ideia de que deve predominar apenas a norma padrão da língua portuguesa em sala, até porque todas as línguas e dialetos são igualmente complexos, nenhum inferior ao outro. O preconceito que se estende ao uso das outras variedades, segundo Camacho (1988), está amarrado a uma tendência evolucionista do final do século XIX, em que se acreditava que quanto mais "primitivo" fosse o estágio cultural de um povo, mais "primitiva" seria a estrutura da língua falada pelo indivíduo.

No nosso país, o processo de colonização favoreceu ainda mais a ideia de que a norma de prestígio fosse sempre a que mais se aproximasse do português europeu. Com a urbanização, a legitimação de uma língua padrão superior às outras variedades se intensificou ainda mais. A vinda da corte portuguesa para o Rio de Janeiro evidenciou ainda mais tal preconceito, já que as peças teatrais ridicularizavam a fala caipira (BORTONI-RICARDO; OLIVEIRA, 2013).

Diante disso, fica evidente o porquê de os professores de língua portuguesa ainda lutarem em sala de aula por uma língua "limpa", sem vestígios da oralidade, do popular, das variedades (ALVES, 2008). Há uma valorização, por parte do professor, do ensino da gramática normativa, e crescente desvalorização de suas variantes.

Revista Educação Online Rio de Janeiro, n. 24, jan-abr 2017, p. 20-37 
Assim, enquanto os fundamentos sociolinguísticos da variação e da mudança, de acordo com Cyranka e Horta (2010), não se tornarem alvos de reflexão escolar sobre e com a linguagem, continuaremos numa luta improfícua, cada vez mais marcada por preconceitos e abordagens inadequadas. É o uso da língua na escola que reflete com clareza as diferenças entre grupos sociais e gera discriminações.

No que se refere à variedade linguística, ainda que os PCN de língua portuguesa reconheçam a existência de variantes linguísticas que devem ser respeitadas, dado que não há uma maneira certa ou errada de se falar, há ainda preconceito. Os professores usam uma variedade de língua que os alunos não compreendem, não levando em conta as experiências linguísticas que os alunos trazem para a escola, demonstrando, em alguns momentos, desconhecer a realidade econômica dos alunos. Esses aspectos prejudicam a interação em sala de aula, condição fundamental para que os alunos participem efetivamente das situações comunicativas e enriqueçam suas experiências com a língua.

Os estudos que têm como foco o ensino de língua portuguesa, em especial nas escolas públicas, revelam a necessidade de uma reorientação na prática pedagógica, devido aos resultados do insucesso escolar que podem ser comprovados pelas dificuldades de leitura que obstaculizam a aprendizagem, pelas dificuldades na produção escrita e nas manifestações orais que exigem a utilização de um estilo mais formal. Podemos acrescentar ainda as altas taxas de repetência e desistência, revelando que os que entram na escola ou não aprendem ou não conseguem nela permanecer (SOARES, 2006). Por outro lado, pode haver uma consequência ainda mais séria, se provocar no aluno a ideia de que são linguisticamente incapazes.

Diante desse quadro desanimador, muitos estudiosos têm-se voltado para pesquisas que buscam motivar uma transformação dessa prática, defendendo que o mais importante não é saber analisar uma língua dominando conceitos e classificações, mas, sim, fazer uso da linguagem em situações concretas de interação, além de compreender e produzir enunciados (ANTUNES, 2003).

Os PCN de língua portuguesa reconhecem a existência de variantes linguísticas, que devem ser respeitadas, pois não há um modo certo ou um modo errado de falar. Há o reconhecimento da língua como veículo de transmissão de cultura, de valores, de preconceitos. De acordo com os documentos do Ministério da Revista Educação Online Rio de Janeiro, n. 24, jan-abr 2017, p. 20-37 
Educação (MEC), saber falar ou escrever bem é falar ou escrever de modo adequado, sabendo qual variedade usar. Para os PCN (1997, p.31-32),

A questão não é falar certo ou errado, mas saber qual forma de fala utilizar, considerando as características do contexto de comunicação, ou seja, saber adequar o registro às diferentes situações comunicativas. (...) A questão não é de correção da forma, mas de sua adequação às circunstâncias de uso, ou seja, de utilização eficaz da linguagem: falar bem é falar adequadamente, é produzir o efeito pretendido.

Os PCNs reconhecem a atual realidade brasileira, em que a estratificação social e a desigual distribuição de renda têm sido consideradas obstáculos para que uma parte da população possa reclamar seus direitos e interesses. Como afirma Bortoni-Ricardo (2005), a estratificação social é visualizada pelo comportamento linguístico. Em uma sociedade como a do Brasil, em que a distribuição de renda desigual se faz presente, perpetua-se também a injusta distribuição de bens culturais e das formas valorizadas de falar (BORTONI-RICARDO, 2005).

Muitas vezes, a deficiência no ensino acontece pelo fato de a escola desconsiderar os antecedentes culturais e linguísticos dos alunos. Para BortoniRicardo (2005), isso acontece devido ao ensino desastroso e inadequado da norma culta, que tem como língua materna variedades populares da língua, o que pode incutir no aluno um sentimento de insegurança, além de a língua padrão não ser ensinada de forma eficiente (BORTONI-RICARDO, 2005).

Diante desse percurso, percebemos que são muitos os esforços empreendidos, seja pelos pesquisadores, seja pelas instituições governamentais, ou por aqueles que defendem uma escola mais formadora e eficiente. Entretanto, apesar desses esforços, ainda é necessário um maior empenho da escola por um ensino de língua mais contextualmente significativo. Para isso, é necessário preparar e orientar esses docentes que se encontram nas escolas públicas, que, apesar da força de vontade, estão desorientados quanto a como lidar com essa diversidade linguística em sala de aula.

\section{Etapas do processo}

Nas primeiras oficinas, fomos a uma turma do $2^{\circ}$ ano do ensino médio, de uma escola pública de periferia, com o objetivo de obter informações, por intermédio de uma produção inicial, sobre quais capacidades de linguagem os alunos detinham em relação ao gênero artigo de opinião. Para isso, levamos os alunos à rua e 
pedimos para eles tirarem fotos e anotarem os problemas do bairro. $O$ objetivo principal era sensibilizá-los sobre o que acontece ao redor da comunidade.

Posteriormente, com o propósito de fazer os estudantes perceberem a relevância do trabalho, apresentamos o projeto, com a finalidade de levá-los à produção de cartas do leitor e a posterior publicação delas no Jornal Escolar.

Para a elaboração desse comando, tomando como base Menegassi (2003), procuramos levar em conta: a finalidade, a especificidade do gênero, lugares preferenciais de circulação e o interlocutor eleito, elementos essenciais que devem ser considerados na construção do texto.

A produção inicial, segunda etapa da sequência didática, permitiu que os alunos se deparassem com dificuldades e obstáculos para a execução da tarefa. Além disso, permitiu que fizéssemos o mapeamento dessas (in)capacidades, prérequisito essencial para a continuidade da sequência didática (DOLZ; GAGNON; DECANDIO, 2009). Nessa fase do trabalho, as produções não receberam uma nota, serviram apenas para indicar os caminhos que devíamos, como educadores, tomar para elaborar as outras atividades da sequência e, portanto, de acordo com Dolz, Noverraz e Schneuwly (2004, p.8), "modulá-la e adaptá-la de maneira mais precisa às capacidades reais dos alunos de uma dada turma".

Nas análises realizadas, primeiramente, procuramos dividir as questões que fazem parte da lista de constatação. Em seguida, apresentamos uma lista de constatação/ controle do gênero em questão, tomando como base Dolz; Schneuwly (2004), e fizemos a avaliação das três capacidades: capacidade de ação (contextualização); capacidade discursiva (estruturação discursiva do texto) e capacidade linguístico-discursiva (seleção de unidades linguísticas para a textualização).

Assim, nesta pesquisa, o que se pretende tratar são apenas as capacidades linguístico-discursivas, em que, tomando como base Bortoni-Ricardo (2005), procuramos realizar a análise e diagnose de erros, a fim de verificar se há erros decorrentes da transposição da fala para escrita. O modelo que desenvolvemos aqui prevê a postulação de categorias de natureza sociolinguística. Trata-se de uma formulação ligada a variáveis morfofonêmicas, que pode e deve ser ampliada.

Revista Educação Online Rio de Janeiro, n. 24, jan-abr 2017, p. 20-37 
Com isso, tomando como base o artigo Análise e diagnose de erros no ensino da língua materna, de Bortoni-Ricardo (2005), foram postuladas as seguintes categorias de erros:

1. Erros decorrentes da própria natureza arbitrária do sistema de convenções da escrita

2. Erros decorrentes da interferência de regras fonológicas categóricas no dialeto estudado.

3. Erros decorrentes da interferência de regras fonológicas variáveis graduais.

4. Erros decorrentes da interferência de regras fonológicas variáveis descontínuas.

5. Erros decorrentes da transposição dos hábitos da fala para a escrita. (BORTONIRICARDO,2005)

$\mathrm{Na}$ categoria (1), foram classificados os erros que resultam do conhecimento insuficiente das convenções da língua escrita. Na língua portuguesa, há fonemas que possuem diversas representações ortográficas, por outro lado, há fonemas que representam dois fonemas (BORTONI-RICARDO, 2005). As diferenças ortográficas do sufixo número pessoal de terceira pessoa do plural /ãw/, que é grafado "ão", quando é tônico, e "am", quando é átono, também estão ligados a essa categoria. Nas demais, estão presentes os erros decorrentes da transposição de hábitos da fala para a escrita.

$\mathrm{Na}$ categoria (2), temos os erros decorrentes da interferência de regras fonológicas categóricas no dialeto estudado. Tal categoria, de acordo com BortoniRicardo (2005), é independente das características sociodemográficas que identificam o falante e do contexto situacional. Foram os seguintes erros que resultaram da interferência das regras fonológicas categóricas no corpus analisado (BORTONI-RICARDO, 2005):

a) Vocábulos fonológicos constituídos de duas ou mais formas livres ou dependentes (MATTOSO, 1975), grafados com um único vocábulo formal. Exemplo: uque, levalo, janotei;

b) Crase entre vogal final de uma palavra e vogal idêntica ou foneticamente próxima da palavra seguinte. Exemplo: a tenção;

c) Neutralização das vogais anteriores /e/ e /i/ e das posteriores /o/ e /u/ em posição pós-tônica ou pretônica;

d) Nasalização do ditongo em "muito" por assimilação progressiva. 
A categoria (3) traz os erros decorrentes de traços da interferência de traços fonológicos graduais. Eles funcionam como indicadores de variedades sociais, diastráticas, além de servir como marcadores de registro entre falantes na língua culta, estando presente, com maior frequência, nos registros não monitorados.

a) Despalatização das sonorantes palatais (lateral e nasal). Exemplo: olhar>>oliar;

b) Monotongação de ditongos decrescentes. Exemplo: beira>> bera; outro>> otru;

c) Desnasalização das vogais átonas finais. Exemplo: homem>> homi;

d) Assimilação e degeminação do /nd/:/nd >>nn>>n/;

e) Queda do /r/ final nas formas verbais.

Nessa categoria, aparecem ainda os erros decorrentes da interferência de regras que modificam ou suprimem morfemas flexionais, levando à modificação nas regras de concordância da língua-padrão. Um exemplo é a alteração ou supressão do sufixo número-pessoal de terceira pessoa do plural dos verbos e a ausência de concordância no sintagma nominal.

a) A língua deles eram um tanto diferente;

b) A linguagem utilizada nas redes sociais, pelos internautas, não seguem a ortografia atual.

$\mathrm{Na}$ categoria (4), encontramos os traços descontínuos, privativos de variedades rurais ou relativas à forte avaliação negativa.

a) Semivocalização do /lh/. Exemplo: velho>>véio

b) Epítese do /i/ após sílaba final travada. Exemplo: paz>>pazi; pessoal >>pesuali

c) Troca do /r/ pelo /I/. Exemplo: sirva>>silva

d) Monotongação do ditongo nasal em "muito">> muntu

e) Supressão do ditongo crescente em sílaba final. Ocorrem dois casos, com ditongo oral e nasal, respectivamente. Exemplo: veio>>vei

f) Simplificação dos grupos consonantais no aclive de sílaba com a supressão da segunda consoante. Exemplo: dentro>>dentu 
g) Metátese em "satisfeito". Nessa categoria, há regras descontínuas que se interseccionam com a morfossintaxe, modificando os padrões de concordância.

\section{Do que nos fala a análise dos textos}

Para a análise, selecionamos duas cartas do leitor, elaboradas por alunos do segundo ano do ensino médio. Os números se referem à classificação nas diversas categorias propostas por Bortoni-Ricardo (2005):

1) Erros decorrentes da própria natureza arbitrária do sistema de convenções da escrita;

2) Erros decorrentes da interferência de regras fonológicas categóricas no dialeto estudado;

3) Erros decorrentes da interferência de regras fonológicas variáveis graduais;

4) Erros decorrentes da interferência de regras fonológicas variáveis descontínuas.

\section{Buero (3) entupido}

Londrina, dia 17 de maio de 2016.

Caro prefeito Alexandre Kirefi...

Estou aqui para reclamar sobre um licho (1) que esta entupido (3) este buero (3) . Esta mal cheroso (3) e esta muito nojento e as pessoa (3) estão reclamando sobre o cheiro que envade (3) a casa.

Possivelmente os mosquitos da dengue estão se reproduzindo com esse buero (3) e pode aver (1) uma epidemia de dengue nas pessoa (3) que moram perto do buero (3).

Mas, meu caro prefeito, esse e só o começo dos ploblemas (3) como ruas emburacadas (3), muro e escolas caídos e atrás das escola (3) tem quase um lixão ao livre, há pessoas joganu (3) lixo, cachorros morto (3) e os alunos reclamando sobre o mal (1) chero (3).

Esta é minha reclamação do Jardim São Lourenço pesso (1) que nos ajude a toma (3) providências imediatas.

Antesiosamente (1):

Revista Educação Online Rio de Janeiro, n. 24, jan-abr 2017, p. 20-37 
A. M

Londrina, 11 de maio de 2016.

Prezado senhor.: Alexandre Kireff

Venho informar oque (2) está acontecendo no Jardim novo Perobal, aqui tem muitos buraco (3) nas ruas e cada vez que carros passam e motos o buraco aumentam (3) cada vez mais e os motociclistas e os pedrestes (3) é perigoso até de cai (3) e quebrar a perna então eu estou escrevendo esta carta para te solicitar dos perigo (3) que estão neste conjunto. Por gentileza vem dar uma olhadinha no Jardim Novo Perobal.

Atenciosamente,

I.K

Nesses dois textos, como foi possível visualizar, há outros problemas ligados à capacidade linguístico-discursiva, como a acentuação, por exemplo, mas isso deixaremos para um segundo momento, já que o objetivo é verificar os erros decorrentes da transposição dos hábitos da fala para a escrita.

Embora haja alguns erros resultantes da própria natureza arbitrária do sistema de convenções da escrita, percebemos a predominância de erros que vêm da interferência de regras fonológicas variáveis graduais. No texto, encontramos ainda uma marca de erros decorrentes da interferência de regras fonológicas categóricas no dialeto estudado e nenhum erro oriundo da interferência de regras fonológicas variáveis descontínuas.

O grande número de erros que decorre da interferência de traços fonológicos graduais nas cartas evidencia a dificuldade em diferenciar a fala da escrita. Enquanto na fala, por exemplo, pronunciamos "buero", na escrita o correto seria "bueiro". Dessa forma, como os alunos dessa escola têm acesso limitado à norma culta em seu meio, acabamos verificando a interferência das regras fonológicas e morfossintáticas de seu dialeto na aprendizagem do português padrão.

\section{Sugestão de trabalho pedagógico}

A análise e diagnose de erros permitiu o levantamento de um perfil sociolinguístico dos alunos-moradores de um bairro periférico em Londrina. Não 
temos aqui a intenção de elaborar uma receita pronta, rígida, até porque cada comunidade escolar e cada aluno possuem suas particularidades. No entanto, há algumas sugestões de atividades que podem ser aproveitadas, antes da refacção final da carta do leitor, a fim de observar se houve evolução por parte do aluno ou não.

a) Levar exemplos do gênero carta do leitor, com a finalidade de levar os alunos a se familiarizarem com a norma padrão. É importante, nesse momento, fazer os estudantes refletirem sobre a importância de se tornarem proficientes em sua própria língua, ou seja, capazes de adequar a linguagem a cada gênero textual.

b) $\mathrm{Na}$ análise, observamos erros decorrentes da interferência de regras que modificam ou suprimem morfemas flexionais, o que levou à modificação nas regras de concordância da língua-padrão. Assim, atividades contextualizadas sobre concordância verbal e nominal se fazem essenciais.

c) No mapeamento inicial, percebeu-se o não uso do /r/ final nas formas verbais. Dessa maneira, por intermédio de exemplos do gênero carta do leitor e reflexões teóricas, o professor poderia chamar a atenção para a necessidade do /r/ no final dos verbos nas produções escritas.

d) Na análise feita inicialmente, constatamos a presença de monotongação de ditongos decrescentes. Exemplo: buero. Assim, atividades gramaticais que levem em conta o uso do ditongo podem fazer os alunos refletirem sobre os erros que têm cometido nos textos.

\section{Considerações finais}

O presente estudo buscou, tomando como base uma sequência didática aplicada em sala sobre o gênero carta do leitor, fazer um levantamento sobre o perfil sociolinguístico dos alunos de uma escola de periferia. Consideramos este trabalho de fundamental importância, uma vez que oferece subsídios para a elaboração de estratégias pedagógicas e de material didático adequado.

Quando um professor conhece as características da fala e da escrita de um determinado grupo social a que pertencem seus alunos, pode planejar seu trabalho em sala com vistas a ampliar as competências dos estudantes, habilitando-os a usar outras variedades linguísticas. Além disso, o professor pode ensinar aos alunos a escreverem de acordo com as convenções ortográficas. 
É essencial que todo estudante aprenda a dominar as convenções da escrita, começando pelas ortográficas, e saiba adequar a linguagem a cada situação de interação. Tal competência se faz essencial, para que ele possa ser bem recebido em diferentes ambientes e, dessa forma, ter mobilidade social.

\section{Referências bibliográficas}

ALVES, M.R.N.R. Educação de jovens e adultos. São Paulo: Parábola Editorial, 2008.

ANTUNES, I. Aula de português: encontro e interação. São Paulo: Parábola Editorial, 2003.

BORTONI-RICARDO, S. M. Um modelo pra a análise sociolinguística do português no Brasil. In: BAGNO, Marcos. Linguística da norma. $2^{\mathrm{a}}$ ed. São Paulo: Loyola, 2004.

Nós cheguemu na escola e agora?: sociolinguística educação. São Paulo: Parábola Editorial, 2005.

; OLIVEIRA, Tatiana de. Corrigir ou não variantes não padrão na fala do aluno? In: RICARDO, Stella Maris; Bortoni-Ricardo; MACHADO, Veruska Ribeiro (Orgs.). Os doze trabalhos de Hércules: do oral para o escrito. São Paulo: Parábola, 2013.

BRASIL/MEC/SEF. Parâmetros Curriculares Nacionais: língua portuguesa. Secretaria de Educação Fundamental. Brasília: Secretaria de Educação fundamental, 1997.

BRONCKART, Jean-Paul. Atividade de linguagem, texto e discursos: por um interacionismo sócio-discursivo. São Paulo: EDUC, 2003.

BRONCKART, Jean-Paul. Atividade de linguagem, discurso e desenvolvimento humano. Campinas: Mercado de Letras, 2006.

. O agir nos discursos - das concepções teóricas às concepções dos trabalhadores. Campinas: Mercado de Letras, 2008.

CALVET, L-J. Sociolinguística - uma introdução crítica. São Paulo: Parábola, 2002.

CAMACHO, R. G. A variação linguística. In: SÃO PAULO Estado. Secretaria da Educação. Coordenadoria de Estudos e Normas Pedagógicas. Subsídios à proposta curricular de língua portuguesa para o $1^{\circ}$ e $2^{\circ}$ graus: coletânea de textos. São Paulo: SE/CENP, 1988. V. I. p. 29-413

CARVALHO, W. L. Metodologia de análise para a localização de escolas em áreas rurais. 2011. Tese (Doutorado em Engenharia civil e ambiental) - Departamento de Engenharia Civil e Ambiental, Universidade de Brasília. Brasília, 2011.

CARVALHO, G. F. S; PORTES, É. A. Preconceito linguístico, norma padrão da língua culta e a escola pública. In: Atos de Pesquisa em Educação. v. 3, n. 1, p.102124, 2008.

CASTILHO, A. T. de. Nova gramática do português brasileiro. São Paulo: Contexto, 2010.

Revista Educação Online Rio de Janeiro, n. 24, jan-abr 2017, p. 20-37 
COSERIU, E. Lições de linguística geral. Rio de Janeiro: Ao Livro Técnico, 1980.

CYRANKA, L. F. M. ; HORTA, B. D. Bidialetalismo na escola pública. Bidialetalismo na escola pública. 1ed.Curitiba: Appris, 2011, v. 01, p. 159-171

. A pedagogia da variação linguística é possível? In: ZILLES, Ana Maria Stahl; FARACO, Carlos Alberto (Orgs.). Pedagogia da variação linguística. São Paulo: Parábola, 2015. 145-191.

DIAS, Juçá Fialho Vazzata. A concordância de número nos predicativos e nos particípios passivos na fala da região sul: um estudo variacionista. 1996. Dissertação (Mestrado em Linguística) - Universidade Federal de Santa Catarina. Florianópolis, 1996.

DOLZ, J. ; SCHNEUWLY, B. Gêneros e progressão em expressão oral e escrita elementos para reflexões sobre uma experiência suíça (francófana). In: SCHNEUWLY, Bernard; DOLZ, Joaquim. Gêneros orais e escritos na escola. Campinas: Mercado de Letras , 2004. p. 41-70.

; NOVERRAZ, Michele; SCHNEUWLY, Bernard. Sequências didáticas para o oral e a escrita: apresentação de um procedimento. In: SCHNEUWLY, Bernard; DOLZ, Joaquim. Gêneros orais e escritos na escola. Campinas, SP: Mercado das Letras, 2004. p. 95-128.

; GAGNON, R. ; DECANDIO, F. Uma disciplina emergente: a didática das línguas. In: NASCIMENTO, E.L. Gêneros textuais: da didática das línguas aos objetos escolares. São Carlos: Claraluz, 2009. p.19-50.

FARACO, C. A. Norma culta brasileira: desatando alguns nós. São Paulo: Parábola Editorial, 2008.

Norma padrão brasileira: Desembaraçando alguns nós. In: BAGNO, M. Linguística da norma. São Paulo: Loyola, 2012. p. 37-61.

FREYRE, G. Rurbanização: Que é? Recife: Massangana,1982.

GERALDI, J. W. Concepções de linguagem e ensino de português. In: . $\mathrm{O}$ texto na sala de aula. Cascavel: Assoeste, 1984. p.41-48.

LABOV, W. The social history of sound change on the island of Martha's Vineyard, Massachusetts. Master's essay. Columbia University, 1962.

. The study of language in its social context. In: Sociolinguistic

patterns. Philadelphia: University of Pennsylvania Press, 1972.

MATTOSO CÂMARA JR, J. Erros escolares como sintomas de tendências linguísticas no português do Rio de Janeiro. In: s/a. Dispersos. Rio de Janeiro: Fundação Getúlio Vargas, 1972. p. 35-46.

REIS, D. S. dos. O rural e o urbano no Brasil. REIS, D. S. O rural e urbano no Brasil. In: ENCONTRO NACIONAL DE ESTUDOS POPULACIONAIS, 15., 2006, Caxambu. Anais... Belo Horizonte: ABEP, 2006. p.1-13.

SOARES, M. Linguagem e escola: uma perspectiva social. $17^{\mathrm{a} e d}$. São Paulo: Ática, 2002. 
2006.

Letramento: um tema em três gêneros. Belo Horizonte: Autêntica,

STREET, B. Letramentos sociais: abordagens críticas do letramento no desenvolvimento, na etnografia e na educação. São Paulo: Parábola Editorial, 2014.

TARALLO, F. A pesquisa sociolinguística. São Paulo: Ática, 2007.

VEIGA, J. E. Desenvolvimento Territorial do Brasil: do entulho varguista ao ZEE. In: ENCONTRO NACIONAL DE ECONOMIA, 29., 2001, Salvador. Anais... Campinas: ANPEC, 2001. v. 1. p. 1-20. 